\title{
Clinical profile and complications of acute malaria caused by different species of Plasmodium
}

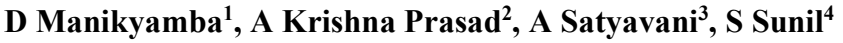 \\ ${ }^{1}$ Dr. D. Manikyamba, Professor and Head, ${ }^{2}$ Dr. A. Krishna Prasad, Associate Professor, ${ }^{3}$ Dr. A. Satyavani, Assistant \\ Professor, ${ }^{4}$ Dr. S. Sunil, Post Graduate. All are affiliated with Department of Pediatrics, Rangaraya Medical College, \\ Kakinada, India
}

Address for correspondence: Dr D. Manikyamba, Email: mani.jonnalagedda@gmail.com

\begin{abstract}
Introduction: Malaria is more severe in children than in adults and $78 \%$ of all deaths due to malaria occur in children under 5years. Plasmodium vivax has long been considered to have benign course. However during past few years several studies reported severe complicated cases of vivax malaria. Methodology: Children in the age group of 6 months to 15 years admitted in the Department of Pediatrics with clinical malaria were tested for malaria using peripheral smear, QBC and rapid diagnostic test. Children with positivity of any of these tests were enrolled in the study. Complete clinical profile is noted. Investigations like complete blood counts, LFT, RFT etc., were done. Results: Out of 150 children enrolled in the study 80 had Plasmodium vivax monoinfection. 61 had Plasmodium falciparum monoinfection and 9 had mixed infection. $41 \%$ of them were under 5 years of age. The incidence of complications like severe anemia $(10 \%$ vs. $18 \%$ ), jaundice ( $10 \%$ vs. $44 \%)$, transaminitis (6\% vs.13\%), azotemia (6\% vs. $36 \%)$ and thrombocytopenia (12.5\% vs. $26 \%)$ were more common in $\mathrm{P}$ falciparum than in $\mathrm{P}$ vivax malaria with statistical significance $(p<0.05)$. There was no statistically significant difference in the incidence of hypoglycemia and cerebral malaria in $\mathrm{P}$ vivax and $\mathrm{P}$ falciparum malaria. Conclusion: The incidence of severe malaria in P. vivax infection is comparable to that in P. falciparum infection and it is no more benign. Hence robust efforts are required for reduction and elimination of $\mathrm{P}$ vivax transmission.
\end{abstract}

Key Words: Plasmodium falciparum, Plasmodium vivax, Clinical Profile, Complicated Malaria,

\section{Introduction}

Globally an estimated 3.3 billion people in 97 countries and territories are at risk of being infected with malaria and developing disease and 1.2 billion are at high risk ( 1 in 1000 chance of getting malaria in year). According to the latest estimates, 198 million cases of malaria have occurred globally in 2013 and the disease leads to 584,000 deaths. $78 \%$ of all deaths due to malaria occur in children aged less than 5 years [1].

Because of immature immune system malaria is more severe in children than in adults. Malaria imposes great socioeconomic burden on humanity and with six other diseases (diarrhea, HIV/AIDS, tuberculosis, measles, hepatitis B and pneumonia) accounts for $85 \%$ of global infectious disease burden.

Manuscript received: $05^{\text {th }}$ Dec 2015

Reviewed: $19^{\text {th }}$ Dec 2015

Author Corrected; $30^{\text {th }}$ Dec 2015

Accepted for Publication: $10^{\text {th }}$ Jan 2016
Among cases of malaria, proportion of Plasmodium vivax and Plasmodium falciparum varies in different parts of India. Areas with more than $30 \%$ of Plasmodium falciparum cases are categorized as high risk.

P.vivax malaria has long been considered to have benign course with multiple relapses. However during past few years several isolated studies from India [2], Indonesia [3,4] and Papua, New Guinea[5] have reported severe complicated cases of vivax malaria. P.vivax is now getting recognized as a major cause of severe and fatal malaria despite its low parasite biomass, increased deformability of infected RBC and apparent paucity of parasite sequestration.

With this background this study was carried out to analyze the clinical profile, laboratory parameters and 
complications of malaria caused by different species of plasmodium.

\section{Methodology}

The present study was a cross sectional observational study conducted over a period of 18 months from December 2011 to May 2013 in the Department of Pediatrics, Government General Hospital, Kakinada. Children in the age group of 6 months to 15 years who were admitted in pediatric wards/ICU with clinical suspicion of malaria were tested for malaria using peripheral smear, QBC and RDT.

Those children with positivity of any of the above mentioned tests were enrolled in the study.
Exclusion Criteria: Children with infections like enteric fever, pyogenic meningitis, tuberculosis etc., with coincidental smear positivity for malaria were excluded in the study.

A predesigned proforma was used to record the sociodemographic details and clinical manifestations of enrolled children. Detailed clinical examination was done and patients were given anti-malarial treatment and complications and outcome were noted. All the enrolled children were subjected to investigations like hemogram, renal function tests, liver function tests and blood sugar. Other investigations like serum electrolytes, $\mathrm{ABG}$, chest $\mathrm{X}$ ray etc., were done whenever required. The results were tabulated and statistically analyzed using SPSS version 17.

\section{Results}

During the study period 450 cases of clinically suspected malaria were admitted in the hospital, of which 150 cases were positive for malaria either by peripheral smear or QBC or rapid diagnostic tests. P.vivax monoinfection was seen in 80 children (53.3\%). P. falciparum was seen in 61 (40.6\%) children and $9(6 \%)$ had mixed infection.

The demographic profile of patients included in the study was shown in table I. $41.3 \%, 34 \%$ and $24.6 \%$ of children were in the age group of $<5$ years, 6-10years and 11-15 years respectively. $52 \%$ of children were males and $48 \%$ were females. $35 \%$ of them were from tribal areas and rest from rural and urban areas.

Clinical profile and lab parameters of children with malaria caused by P.vivax, P. falciparum and mixed infections were given in table II and table III.

All children presented with fever. History of chills was present in $93 \%$ of P.vivax and $95 \%$ of P. falciparum malaria cases. Myalgias (40\% vs. $70.4 \%$ ), vomitings (38\% vs. $62 \%$ ), oliguria $(12.5 \%$ vs. $24.5 \%)$, cerebral malaria (25\% vs. $33 \%)$, jaundice $(10 \%$ vs. $44 \%)$ and organomegaly (54\%vs. $84 \%)$ were more common in children with P. falciparum malaria than in children with P.vivax malaria. Elevation of AST and ALT (6\% vs. 13\%), azotemia (6\% vs. $36 \%)$, severe anemia $<5 \mathrm{gm} \%(10 \%$ vs. $18 \%)$ and thrombocytopenia $(12.5 \%$ vs. $26 \%)$ were more common in children with $\mathrm{P}$. falciparum malaria than with P.vivax malaria.

Table I: Demographic characteristics

\begin{tabular}{|l|l|c|c|}
\hline \multirow{4}{*}{ Age } & & No of children & Percentage \\
\hline & $6 \mathrm{~m}-5 \mathrm{yrs}$ & 62 & 41.4 \\
\cline { 2 - 4 } & $6-10$ yrs & 51 & 34 \\
\cline { 2 - 4 } & $11-15$ yrs & 37 & 24.6 \\
\hline \multirow{3}{*}{ Sex } & Male & 78 & 52 \\
\cline { 2 - 4 } & Female & 72 & 48 \\
\hline \multirow{2}{*}{ Residence } & Tribal & 52 & 34.7 \\
\cline { 2 - 4 } & Urban \& rural & 98 & 65.3 \\
\hline
\end{tabular}


Table II: Clinical profile of children with malaria

\begin{tabular}{|c|c|c|c|c|c|c|c|c|}
\hline $\begin{array}{c}\text { Clinical } \\
\text { Features }\end{array}$ & P.vivax & \% & P.falciparum & \% & mixed & \% & total & \% \\
\hline Fever & 80 & 100 & 61 & 100 & 9 & 100 & 150 & 100 \\
\hline Chills & 74 & 92.5 & 58 & 95 & 8 & 88.8 & 140 & 93.3 \\
\hline Myalgias & 32 & 40 & 43 & 70.4 & 6 & 66.6 & 81 & 54 \\
\hline Vomitings & 30 & 37.5 & 38 & 62.2 & 6 & 66.6 & 74 & 49.3 \\
\hline Oliguria & 10 & 12.5 & 15 & 24.5 & 3 & 33.3 & 28 & 18.7 \\
\hline Hepatomegaly & 11 & 13.7 & 28 & 46 & 8 & 89 & 47 & 31.3 \\
\hline Splenomegaly & 43 & 53.7 & 51 & 83.6 & 9 & 100 & 103 & 68.6 \\
\hline Cerebral malaria & 20 & 25 & 20 & 32.7 & 2 & 22.2 & 42 & 28 \\
\hline Jaundice & 8 & 10 & 27 & 44.2 & 2 & 22.2 & 37 & 24.7 \\
\hline
\end{tabular}

Table III: Lab parameters in children with malaria

\begin{tabular}{|c|c|c|c|c|c|}
\hline Parameter & P.vivax & $\mathbf{\%}$ & P.falciparum & \% & P value \\
\hline Anemia & 30 & 37.5 & 46 & 75.4 & 0.000 \\
\hline Thrombocytopenia & 10 & 12.5 & 16 & 26.2 & 0.037 \\
\hline Deranged RFT & 5 & 6.25 & 22 & 36 & 0.000 \\
\hline Elevated transaminases & 5 & 6.25 & 8 & 13.1 & 0.000 \\
\hline Hypoglycemia & 2 & 2.5 & 3 & 4.9 & 0.442 \\
\hline $\begin{array}{c}\text { Hyperbilirubinemia } \\
(\text { TSB }>1.5 \mathrm{mg} / \mathrm{dl})\end{array}$ & 8 & 10 & 27 & & 0.000 \\
\hline
\end{tabular}

Table III shows comparison of morbidity profile of P.vivax and P. falciparum infections. All the complications of malaria were more common with P. falciparum than with P.vivax infection.

It was observed that severe anemia, thrombocytopenia, azotemia, transaminitis and jaundice were more common with P. falciparum with statistical significance $(p$ value $<0.05)$. There was no statistically significant difference in the incidence of hypoglycemia and CNS manifestations in P.vivax and P. falciparum malaria.

Table-IV: Clinical features and lab parameters in children of different age groups with P.vivax and P. falciparum infection

\begin{tabular}{|c|c|c|c|c|c|c|}
\hline & \multicolumn{2}{|c|}{$6 \mathrm{~m}$ - 5years } & \multicolumn{2}{|c|}{$6-10$ years } & \multicolumn{2}{|c|}{$>10$ years } \\
\hline & $\mathbf{P v}$ & $\mathrm{Pf}$ & $\mathbf{P v}$ & $\mathrm{Pf}$ & $\mathbf{P v}$ & $\mathbf{P f}$ \\
\hline Splenomegaly & $17(21 \%)$ & $15(24 \%)$ & $14(17.5 \%)$ & $23(37 \%)$ & $12(15 \%)$ & $13(21 \%)$ \\
\hline Hepatomegaly & $6(7.5 \%)$ & $6(9.8 \%)$ & $3(3.75 \%)$ & $14(23 \%)$ & $2(2.5 \%)$ & $8(13 \%)$ \\
\hline Cerebral malaria & $6(7.5 \%)$ & $5(8 \%)$ & $7(8.7 \%)$ & $9(15 \%)$ & $7(8.8 \%)$ & $6(10 \%)$ \\
\hline Raised bilirubin & $3(3.7 \%)$ & $8(13 \%)$ & $4(5 \%)$ & $13(21 \%)$ & $1(1.2 \%)$ & $6(10 \%)$ \\
\hline Elevated transaminases & $1(1.2 \%)$ & $3(4.9 \%)$ & $3(3.75 \%)$ & $3(4.9 \%)$ & $1(1.2 \%)$ & $2(3.2 \%)$ \\
\hline Abnormal RFT & - & $6(9.8 \%)$ & $4(5 \%)$ & $11(18 \%)$ & $1(1.2 \%)$ & $5(8 \%)$ \\
\hline Anemia & $8(10 \%)$ & $14(23 \%)$ & $12(15 \%)$ & $21(34 \%)$ & $10(12 \%)$ & $11(18 \%)$ \\
\hline Thrombocytopenia & $3(3.7 \%)$ & $4(6.5 \%)$ & $3(3.75 \%)$ & $8(13 \%)$ & $4(5 \%)$ & $4(6.5 \%)$ \\
\hline
\end{tabular}


Table IV shows the age wise incidence of various complications of P. falciparum and P.vivax malaria. There was no significant difference in the incidence of complications of P. falciparum and P.vivax malaria in different age groups.

\section{Discussion}

In the present study highest prevalence of malaria was seen in children of age less than 5 years $(41 \%)$. This is in contrast with the studies done by Ragini et al[6] and Pankiti D Desai et al[7], where children above 6 years are more commonly affected; this can be explained by high endemicity in this area.

Plasmodium falciparum accounted for $40 \%$ of hospitalized malaria cases in the present study, whereas Koushik et al[8] from Delhi and Ragini et al from uttarakhand[6] showed lower prevalence of Plasmodium falciparum ( $7.9 \%$ and $28 \%$ respectively).

In the present study hematological, renal and hepatic complications were noted more commonly in $\mathrm{P}$. falciparum infection. The incidence of CNS complications was similar in P.vivax and P. falciparum infections.

Jaundice was seen in $44 \%$ and $10 \%$ of P. falciparum and P.vivax malaria whereas transaminitis was seen in $13 \%$ and $6 \%$ of P. falciparum and P.vivax malaria. These results indicate that besides hemolysis, hepatocellular injury is important factor for jaundice.

The occurrence of transaminitis (elevated AST and ALT) indicates "malarial hepatitis", but co-existent infections like hepatitis A also have to be ruled out.

In the present study cerebral malaria was seen in $25 \%$ and $33 \%$ of P.vivax and P.falciparum infection. Two studies on children from Bikaner [9] and Uttrakhand [10] showed a comparable incidence of cerebral malaria between P. vivax and P. falciparum infections.

Thrombocytopenia was seen in $26 \%$ and $12 \%$ of P.falciparum and P.vivax malaria in present study. Earlier observations found that thrombocytopenia is quiet rare in P.vivax malaria but recently thrombocytopenia has been noted in P.vivax monoinfection from many parts of world including India $[11,12,13,14]$.

Renal dysfunction was seen in 6\% of P.vivax infection in this study. A study from Bikaner reported $10 \%$ incidence of renal dysfunction in P.vivax malaria. Several other studies [11, 15] reported acute renal failure in P.vivax infection
The present study analysis shows that the incidence of severe malaria (including cerebral malaria) in vivax infection is comparable to that in $\mathrm{P}$. falciparum infection

The inability of the infected RBC to adhere to vascular endothelium and the parasite's strict preference for invading reticulocytes could explain the benign nature of P.vivax infection.

Infected RBC in P.vivax is not as rigid as observed in P. falciparum infection which makes capillary blockage in organs less likely in P.vivax infection. But several reports of occurrence of severe malaria with P. vivax show the need to decipher the pathogenesis of severe malaria caused by P.vivax.

The geographical areas that reported severe P.vivax malaria are the same that demonstrated P.vivax chloroquine resistance [16]. Hence further studies are required to find out the relation between the pathogenesis of severe malaria and its relation to emergence of multidrug resistant strains of P.vivax.

The WHO severity criteria formerly only validated for P. falciparum infection seem to be applicable to most of the P.vivax patients. But certain criteria need to be readdressed. Severe disease with P. falciparum is considered with parasitemia of $>2,00,000 / \mu 1$, while parasitemia exceeding $50,000 / \mu 1$ is rare in severe P.vivax malaria[17]. P.vivax causes potentially life threatening infection at relatively low grade parasitemia.

There are abundant data showing that transmission of $\mathrm{P}$. falciparum is actually more responsive to malaria control measures. As a result, in areas where two species co-exist, the scale up of integrated malaria control measures generally result in a shift, such that P.vivax becomes dominant species [18]. Globally malaria control strategies and action plan needs to readdress the fallacy that P.vivax is 'benign', not fatal. More robust efforts are required for reduction and elimination of P.vivax transmission to achieve Millennium Development Goal 6 (the goal of no deaths from malaria and malaria free world), which specifically addresses malaria. Malaria control also helps to achieve other MDGs. 


\section{Conclusion}

The present study shows that P.vivax monoinfection can result in severe malaria in children and more robust measures are required to reduce the transmission of P.vivax malaria to achieve MDGs.

\section{Abbreviations \\ QBC: Quantitative buffy coat \\ RDT: rapid diagnostic test \\ LFT: liver function tests \\ RFT: renal function tests \\ HIV: human immunodeficiency virus \\ AIDS: acquired immune deficiency syndrome \\ RBC: red blood cell}

\section{References}

1.

www.who.int/malaria/publications/world_malaria_repo rt_2014.

2. Tripathy R, Parida S, Das L, Mishra DP, Tripathy D, Das MC, Chen H, Maguire JH, Panigrahi P. Clinical manifestations and predictors of severe malaria in Indian children. Pediatrics. 2007 Sep;120(3):e454-60.

3. Barcus MJ, Basri H, Picarima H, Manyakori C, Sekartuti, Elyazar I, Bangs MJ, Maguire JD, Baird JK. Demographic risk factors for severe and fatal vivax and falciparum malaria among hospital admissions in northeastern Indonesian Papua. Am J Trop Med Hyg. 2007 Nov;77(5):984-91.

4. Tjitra E, Anstey NM, Sugiarto P, Warikar N, Kenangalem E, Karyana M, Lampah DA, Price RN. Multidrug-resistant Plasmodium vivax associated with severe and fatal malaria: a prospective study in Papua, Indonesia. PLoS Med. 2008 Jun 17;5(6):e128. doi: 10.1371/journal.pmed.0050128.

5. Genton B, D'Acremont V, Rare L, Baea K, Reeder JC, Alpers MP, Müller I. Plasmodium vivax and mixed infections are associated with severe malaria in children: a prospective cohort study from Papua New Guinea. PLoS Med. 2008 Jun 17;5(6):e127. doi: 10.1371/journal.pmed.0050127.

6. Singh R, Kumar S, Rana SK, Thakur B, Singh SP. A comparative study of clinical profiles of vivax and falciparum malaria in children at a tertiary care centre in uttarakhand. J Clin Diagn Res. 2013 Oct; 7(10):22347. doi: 10.7860/JCDR/2013/6914.3479. Epub 2013 Sep 18.
7. Desai Pankti D, Vasavda Halak, Vora Hetal D, Mansuri S H, Patel Bhavesh. Clinical spectrum, complications \& treatment outcomes of malaria (in pediatric patients). National Journal of Integrated Research in Medicine. 2013 Mar-Apr; 4(2): 140-143.

8. Kaushik JS, Gomber S, Dewan P. Clinical and epidemiological profiles of severe malaria in children from Delhi, India. J Health Popul Nutr. 2012 Mar;30(1):113-6.

9. Kochar DK, Tanwar GS, Khatri PC, Kochar SK, Sengar GS, Gupta A, Kochar A, Middha S, Acharya J, Saxena V, Pakalapati D, Garg S, Das A. Clinical features of children hospitalized with malaria-a study from Bikaner, northwest India. Am J Trop Med Hyg. 2010 Nov;83(5):981-9. doi: 10.4269/ajtmh.2010.09-0633.

10. Singh R, Kumar S, Rana SK, Thakur B, Singh SP. A comparative study of clinical profiles of vivax and falciparum malaria in children at a tertiary care centre in uttarakhand. J Clin Diagn Res. 2013 Oct;7(10):22347. doi: 10.7860/JCDR/2013/6914.3479. Epub 2013 Sep 18.

11. Kaur D, Wasir V, Gulati S, Bagga A. Unusual presentation of Plasmodium vivax malaria with severe thrombocytopenia and acute renal failure. J Trop Pediatr. 2007 Jun;53(3):210-2. Epub 2007 Jan 30.

12. Thapa R, Biswas B, Mallick D, Sardar S, Modak S. Childhood Plasmodium vivax malaria with severe thrombocytopenia and bleeding manifestations. J Pediatr Hematol Oncol. 2009 Oct;31(10):758-9. doi: 10.1097/MPH.0b013e3181b7eb12.

13. Harish R, Gupta S. Plasmodium vivax malaria presenting with severe thrombocytopenia, cerebral complications and hydrocephalus. Indian J Pediatr. 2009 May;76(5):551-2. doi: 10.1007/s12098009-0087-0. Epub 2009 Apr 23.

14. Bhatia V, Bhatia J. Severe thrombocytopenia with bleeding manifestations in two children secondary to Plasmodium vivax. Platelets. 2010;21(4):307-9. doi: $10.3109 / 09537100903518278$.

15. Saharan S, Kohli U, Lodha R, Sharma A, Bagga A. Thrombotic microangiopathy associated with Plasmodium vivax malaria. Pediatr Nephrol. 2009 Mar;24(3):623-4. doi: 10.1007/s00467-008-0945-4. Epub 2008 Aug 8. 


\section{Research Article}

16. Lacerda MV, Fragoso SC, Alecrim MG, Alexandre MA, Magalhaes BM, et al (2012) Postmortem characterization of patients with clinical diagnosis of Plasmodium vivax malaria: to what extent does this parasite kill? Clin Infect Dis 2012 Oct;55(8):e67-74. Epub 2012 Jul 6
17. Shaikh S, Memon H, Iohano B, Shaikh A, Ahmed I, Baird JK. Severe disease in children hospitalized with a diagnosis of Plasmodium vivax in south-eastern Pakistan. Malar J. 2012 May 2;11:144. doi: 10.1186/1475-2875-11-144.

18. www.who.int/entity/malaria/mpac/sep2012/p vivax

\section{How to cite this article?}

D Manikyamba, A Krishna Prasad, A Satyavani, S Sunil. Clinical profile and complications of acute mal aria caused by different species of Plasmodium. Pediatr Rev: Int J Pediatr Res 2016;3(1):13-18.doi:10.17511/ijpr.2016.i01.04. 